\title{
Foreign Language Classroom: Multilingual and Multimodal Space?
}

\author{
Margarita Gudova*, Maria Guzikova, Olga Kocheva, and Alberto Cardenas Bucheli \\ Ural Federal University, 62000219 Mira street Ekaterinburg, Russia
}

\begin{abstract}
The article is focused on the elaboration of the theory of multiliteracy developed by the New London Group in the mid-1990s, with a special emphasis on multilingualism as a challenge for the teachers of English who need to acquire a new understanding of the rapidly changing learning environment shaped by the multitude of language repertoire performed in the classroom. The modern language communication necessitates a more dynamic way of interpreting and processing the information received through the construction of a personal search trajectory. Multimodal literacy as the goal of modern education requires developing of the ability to actualize meanings through the personal modality and narratives. The new educational context should be equally important and accepted by every participant engaged in the educational process, as well as, if necessary, be supplemented by new modalities. The English teachers' experience of integrating multiliteracies into their practice is shown through the narrative enquiry approach.
\end{abstract}

\section{Introduction}

Today we observe the rapid development of digital and automated technologies, and we see how fast they become integrated into our existence. This change brings about fundamental questions about the place of the human in this digitalized environment and about the changes this technological revolution implies for the shape of the human society, professions and activities. Every activity which can be automated will soon be carried out by robots, and already in 2013 an Oxford research estimated that about $50 \%$ of all jobs in US are going to be carried out by machines [1]. This perspective was foreseen a while ago, as in 1933 John Maynard Keynes famously predicted that the technological advancement will bring about a large-scale unemployment. However, only with the fast progress in machine learning and artificial intelligence has this discussion been transformed into a matter of a wide public debate.

These developments represent a dramatic change of a context of learning and have profound implications for the theory and practice of education. They led to an understanding of an urgent need for a type of literacy that would be appropriate for our times and could account for integrating technology into the process of the meaning-making. Technological development, and first and foremost, computerization and digitalization, makes a person who can be called literate in the traditional way; it means being in command of the body of knowledge, replaceable by a machine in the nearest future. However, those who know how to apply this body of knowledge in the new situations, to think of new solutions, synthesize and express knowledge in multiple ways; those, who know how to navigate change and collaborate, who are able to constantly learn with the change, are likely to become professionals of the future. These people are to become literate in a new way, where meaning-making happens in a fluid, constantly changing technological environment. Another important aspect of the change is the growth of multilingualism, and the turn of communication into an increasingly culturally diverse space where people of different ethnicities speak varieties of English as a new lingua franca [2]. The multilingual turn and the spread of English is connected with the fact that technologies contribute to the mobility, and people opt for one means of communication which, in turn, is represented in a variety of ways. The challenge for the evolvement of this new type of literacy requires teachers and learners to understand the ongoing change in the educational process in which literacy, technology and communication will shape one another.

How do teachers perceive these changes? Do they view the process of literacy to turn from the traditional written text-bound type to the multiplication of texts in images, sounds, movements and so on? Are they advocating the use of technology or are they rejecting it because they were socialized before the widespread adoption of digital technology? If they acquired the notion of multiple literacies and introduced it into their teaching, what are their preferred practices of semiosis? Do they introduce the notion of English as a modern lingua franca to their students? If yes, what kind of norm do they present their students with? These are the questions we decided to ask the English teachers of the Ural Federal University in Ekaterinburg to show-case the spread of the multimodality and multilingualism ideas which were conceptualized in the theory of the multiliteracies by the New London 
Group in the mid-1990s [3, 4]. Employing a narrative inquiry approach, English teachers' experience is presented with an emphasis on their perceptions and efforts of integrating multiliteracies into their classrooms.

\section{Theoretical framework}

The term "multiliteracy" was coined by the New London Group along with their efforts to refine the concept of post-literacy. The agenda of the New London group concerned many aspects of developing new approaches to learning and pedagogy, with the main focus on two "multi" - the notion of multimodality and the notion of multilingualism [4]. Multimodality of information and its implications for learning were elaborated by British social semiotician Gunther Kress. Kress took as a principle of his reasoning the idea of language of culture and considered its main functions - representative and communicative. In his book "Literacy in the New Media Age" [5] Kress wrote that one cannot talk about literacy without taking into account social, technological and economic factors. He believed that two distinctions in relation to literacy should be emphasized: on the one hand, the transition from the dominance of letters to the domination of the image and, on the other hand, the transition from a book as a medium to a screen of a gadget. The two events have revolutionized thinking about literacy and notions about representation and communication, related to literacy. All that has raised a number of questions: what is the future of literacy, what are the long-term social and cultural effects of these changes, and how will changing media impact education?

The main point of the Kress' ideas is that modern communication taking place simultaneously in three media paper, analog and digital - requires new integrated skills to work with texts and absorb data included in them. Paper media, like books, newspapers, magazines, leaflets and brochures, require from their creators traditional forms of written and drawing literacies and skills in a variety of genres and styles of writing and graphics. Analog media, like TV and radio, involve other forms of literacy and competences: online or image work, creation of a program of a specific genre and composition, compliance with specific production technologies, use of certain effects when broadcasting information from TV or radio studio, etc. Literacy is completely different in the new media, where verbal and visual, radio or television studio texts and texts of mobile photography and mobile video are combined in the one space of the screen. The fact of a multimodal semiosis multiples the layers of communication in the modern world and poses the need to educate professionals for various kinds of communication.

The transition from knowledge procedure, proposed by the author in the text, to the open scheme, noticed by the user on the screen of the gadget, can be traced. Kress analyzes the structure of the text and states that a book page is single, while the screen is multipage, consisting of several textual, verbal and video pages. The old way supposes knowledge production by the author for the reader; the new method lets the reader/user produce knowledge. In the world of literacy the author knows the readers' life-world and produces the necessary knowledge, while in the world of post-literacy web-page designers place the knowledge characteristic to the users' life-world. In the world of literacy (world of books or belles-lettres) the reader's path is fixed (from left to right and top to bottom), while in the era of post-literacy the user's path is free and determined by his interest. When the author defines landmarks for the reader, the user defines the input-output and his trajectory. When writing and its rules define the structure of the text, illustrations dominate the web-page, and information value and suggestibility are higher than that of an ordinary verbal text. In the first case, the focus is on the work with the text and knowledge, and in the second case, it is on the new non-canonical modes. Both ways of working with the data reflect a state of society, culture and economy, and Kress terms the second way as post-literacy.

Speech communication, occurring as both day-to-day and radio and television messages, remains the leading communication method in the media space, and hence the need for special training of competent and euphonic speakers. Writing as a way of communication will be pressed in many fields of public communication and will remain fundamental only to political and cultural elite, since it bears the certainty of fixed value. For communications professionals this means that full mastery of written literacy should be achieved. The image, produced with the help of graphics, photos, videography and infographics, will dominate in instant messaging. Hence the need for "visual" iconographic or icon literacy, since the main array of information will be transmitted in this manner.

Kress stated that the new electronic media have three long-play effects on the future. The first effect is produced by combining different information channels: verbaltextual, visual and auditory, which generates multichannel and multimedia mode. The second effect is in facilitation of multilateral interaction of participants in communication due to interpersonal nature of the new media. The third effect arises from a different interaction between texts, since it becomes hypertextual. This implies absence of authorship, so the text can be instantly converted by the recipient in any way: transformed into sound or image, moved or split, etc. Consequently, the second aspect of the creative essence of the concept of post-literacy explains that the modern culture accumulates texts of diverse forms and origins in a single hypertextual information flow, which requires the ability to form a personal retrieval route. All these changes in culture necessitate a shift in understanding of literacy and education, including respecting different languages that facilitate communication. The old views should make way to new post-literal ones. Therefore, "literacy pedagogy now must account for the burgeoning variety of text forms" [3].

The discussion of multilingualism as variability within one language, including discursive differentiations, accompanied the elaboration of the concept of multimodality. One of the main proponents of the multilingualism approach of the new literacies in the New London Group was Courtney Cazden, who, being influenced by Vygotskian ideas, proposed the introduction of a multisensory education for schools with pupils from different cultural backgrounds as early as in 
1976. She said that some "pupils may be depressed in overly verbal (sic!) environment" [6]. Camden drew attention to the fact that classroom is a very crowded environment where spoken communication predominates. Spoken language is not only means of communication in the classroom but also a way to express identities of all classroom participants. That is why variations in ways of speaking - individual, collective, among pupils, murmuring something to a neighbor and so on - is what constitutes learner's experience there. Cazden stated that people come to the classroom from different linguistic background, meaning not only representatives of various languages, but mainly the differences in how and when something is said.

Classroom discourse is not only what happens among students and teacher, but it is also an internal process taking place within each pupil or student during their learning. Cazden drew attention to the question, how the words spoken in classrooms affect this learning, and therefore, the nature of how they learn and how relationships among individual development and interaction within a social context can be best understood. Thus, she focused on the fact that any change in students' academic and personal development should be accompanied by the change of language and discourse used in the classroom. She suggested that a tacit cultural knowledge of children and their different learning styles must be taken into account for the elaboration of teaching repertoires. She also criticized the Eurocentric way of knowledge transmission because of the passive role of pupils leading to their lack of self-expression and the loss of self-esteem in this environment. [7] In her work "Classroom Discourse" Cazden emphasized the need to shift from a classroom dominated by teacher talk to a more dialogical one. She thus extended the meaning of the term multilingualism by including the multiplicity and variety of different discourses and ways of talking.

\section{Discussion and Results}

In his article "Gains and Losses: New Forms of Text, Knowledge, and Learning", G. Kress considered the features of post-literacy in the context of the information culture [8]. What the British scientist thought to be an academic problem of differentiating between the old and the new way of representing and transmitting knowledge, the Russian educators consider the difference between generations of education standards for higher education. The old way (the previous generation of educational standards) of transferring knowledge implemented textual reception, using writing/reading and books as mediators, while the new way (the current generation of educational standards) presupposes a synthetic unity of the different modes of information transfer. This being said, educators emphasize that they mainly address textual and visual information, sometimes using video images with a screen as the intermediary.

The narratives of educators clearly state that they see the difference between the old way to teach literacy which they describe as the knowledge type, referring to the mental structures of the trainee's psyche and based on memorizing data and its verbal reproduction, and a new method of information transfer which is supposed to become operationally efficient and dynamic, as it must develop data processing skills in different languages. The skills include generating, evaluating, interpreting, transforming and transmitting knowledge. Knowledge is not only to be transmitted from the teacher to a learner, but allowed one to have a personal hand in. The modern linguistic education, according to what teachers say, should assume as its basis the principle of "the intuitive interface": a system of visual cues that assist students in absorbing large amounts of skills and further perfecting them in joint activities with the experienced teacher.

Teachers report that they actively use the concept of blended learning and the technology of the flipped classroom. However, teachers complain about the lack of students' interest to actively co-create the learning space and refer to a sometimes frustratingly low level of students' motivation and initiative-taking. Teachers suppose that the reason for the students' un-willingness to make decisions about their learning is their habit to learn for tests only, which dominates high school years due to the need to pass the United State Exams. The fact that the exams are all written and there is no need to focus on developing speaking skills is attributed by the teachers to noticeable decrease of students' English speaking skills. Teachers find it remarkable that the culture of test-taking is in sharp contrast with the discourse of developing more than just a knowledge command.

The use of technology for teaching is not always a matter of course for all teachers. Some of them say that they are "digital immigrants" and feel that their students are well ahead of them. However, none of them rejects the use of technology because one, as some say, should keep up with the times. They make an observation that striving to bring to the classroom authentic texts and letting the students listen to the authentic sounds of English encouraged teachers to use technology, starting with the foreign newspapers and magazines and ending with the Youtube videos and podcasts. There is, however, a widespread anxiety that in the nearest future teachers of English might lose jobs: "We will be substituted by elearning courses". They feel that the urge to computerize the process of education might also be rooted in the wish to make the learning results more predictable, and the learning process more accountable and transparent by eroding the "human factor". On the other hand, those who feel confident with technology, "tech-savvy", advocate it and see new opportunities.

Teachers are well aware that we live in the world where visual information is more easily acquired, but they feel sorry that the book as the once leading mode of information transfer makes room to the screen. They say that within the framework of the traditional literacy the idea was to take the knowledge with you, and now the knowledge is always available for use, with portable devices. But this availability does not equal operationalization. Teachers claim that this easy access to knowledge does not lead to the evolvement of systematic and critical thinking. As one of them said, "prior to you know how, you just have to know". So, teachers are aware that transmitting knowledge might not be the idea of education any more, but they struggle to see how to scale it up to the level of synthesizing and creativity. 
The multilingual environment, natural for many Russians, is an online community and international electronic correspondence. It is in the mobile Internet space where the explosive growth of communication between representatives of different countries and different languages is taking place. The number of multilingual people who use the Internet today dominates the number of monolingual users, considering how many people in the world learn a foreign language or languages and are, therefore, at least receptive bi- or multilinguals. Also, the important factor is openness of multilingual (English, Spanish or Russian) international network of communities, and closure of network communities that use only local languages, having a narrow distribution in the world and lacking machine translation tools.

The bulk of communication through the Internet is in English, which has become a modern lingua franca [9]. The lingua franca communication takes place primarily among people for whom English is not their native language [10]. Apparently, the lingua franca solves the problem of linguistic pluralism with the tacit agreement of the parties concerned. Many teachers mention that people in the Facebook posts or in blogs often use or refer to the English expressions along with a Russian text. Consequently, teachers do not need to convince their students of the value of learning English to successfully network.

Speaking about English as a lingua franca, teachers notice that, in theory, there is no need to follow the ideal of pronunciation, grammar and intonation, as the chances to communicate with non-native English speakers are higher. The non-native English speakers lack criterion allowing them to assess pronunciation and the adequacy of the idiomatic expressions used, as well as intonation. This means that often the international English communication is practiced with the limited possession of communication tools, whether imperfect phonetics, shortage of vocabulary or errors in grammar. The effective and successful communication in the international English depends not so much on the English level, but on the ability to communicate and "find and seek for meanings" [11]. Although teachers are aware of the implications of the English as a lingua franca, they are dubious about the effects these implications have for their teaching practice. Unlike technology which is perceived as a neutral requirement, English teaching lies at the core of the respondents' profession. They are less willing to acknowledge the change and the disappearance of the standard of teaching because they identify their job with its transmittance. The same hesitancy concerns such classroom practices as translanguaging, code-switching or diglossia, presupposing employment of multilingual semiotic resources. Teachers defend their way of classroom communication in foreign language only. They express their belief that communicating in foreign language maximizes the value for students.

One of the most sensitive topics of discussion is the classroom interactions and the teacher's role in moderating discussions. Although respondents speaking style is often described by them as welcoming students to express themselves, some anxiety and defensiveness is often felt behind it. A few teachers are really happy with their classroom interaction results. Some claim that students are rarely interested in such interactions and that they are prone to the authoritative instruction, others say that the discussion dies out soon. Some say that students are interested in the development of language, not communication competence. Teachers also notice that technology and online writing require teaching a range of compensatory means of non-verbal communication, which enable expressing the emotional nuances of the spoken language and the direct emotional response, which also require their competent reading and interpretation. As a result, the multilingual Internet space asks for the skills that have been acquired through networking and multimodal communications skills.

As the thematic analysis of the teachers' narratives suggests, the majority of educators are open to the use of technology in the teaching practice. Some welcome technological novelties, some shun them, but all are unified in the understanding that this is the future. Not to use technology equals being outdated. Those who are more positive towards multimodality of literacies see opportunities for students and developing skills for teachers. In best-scenario case, technology and multimodality get wired into the meaning-making process. As for the varieties in their subject, as teachers define foreign language, and in the diversification of the classroom discourse repertoires, the answers vary from acknowledgment of English as lingua franca to its rejection and from a more positive awareness of the varieties of classroom management styles to a more reserved response.

\section{Concluding remarks}

It is in the works of the New London Group that the conceptualization of the concept of multiliteracies is taking place. In the $1990 \mathrm{~s}$, books and screen were the main modes of the information transfer, and the ability to work with the book implied the traditional old literacy, while the ability to retrieve information from the screen and operate with it suggested the use of the multimodal approach. For the authors of the New London Group multiliteracies mean a reference to the era of combinations of different forms of literacy, including the emergence of information literacy, i.e. competent work with new media.

In terms of the substantial characteristics of the new literacy, Kress, for example, believes that the notion of multimodal literacy is more productive because it tackles the two following points: the new literacy exists for different ways of information transfer (verbalalphabetical, visual and auditory); just as these different ways of information transfer collocate in the digital age (multimedia superhighway), so too should different types of literacy (alphabetical, visual and audial) be combined in a single multimedia literacy. Nowadays, the multiliteracies ideas have been captured and developed, among others, by the Russian researchers who are focused on the problems of modern literacy and the role of reading in these processes, including multilingual environment.

In our view, the conception of multimodal and multilingual literacy is inextricably linked with the development of a new learning environment that is 
friendly, but all the same, provides room to independently examine and make meanings through the preferred modality. In the era of post-literacy, any unification takes a back seat; the old constructs have become obsolete and are gradually being filled with the new and innovative, such as "flipped learning", pioneered by A. Sams and J. Bergmann [12]. Ten years since its creation, as a form of blended learning - viewing video lectures offline before the analysis of the fragments, which represent the difficulty, together with the teacher and the group in the classroom - the model is gaining the increasing popularity as it tackles the tasks that traditional approach to teaching only declared: personalization of the learning space, development of critical thinking, and technological effectiveness of education.

However, it is not worth idealizing and hoping that the new technological context will lead to the full introduction of multiliteracies as they were conceived by their creators. Technology transforms the process of teaching, but it does not solve the eternal problem of academic motivation in general and subject-specific interest in students. Motivation is solved by the instrumental methods, and much is written about it. The interest in learning and improved attention can be achieved, but not for long, and again a new "supporting block" should be constructed. The problem is rather metaphysical, and in the post-literacy era its topicality is not reduced. Apparently, the concept of modern education lacks meaning, and all the persons interested in the qualitative learning are searching for it.

Similar to Neil Postman [13], we believe that modern education needs a new narrative, as the narrative provides the necessary meanings (identity and sense of belonging to the group), which every individual derives through a modality that is meaningful only for them. This new narrative must be accepted by all the participants of the educational process as their own and it should replace less productive concepts, such as economic profitability, ideology of consumption, technology and multiculturalism, which are "false gods" by Postman.

Currently, the Russian academic community is attempting a difficult task of giving new meanings to the content of education with an eye to the future university graduates, who are supposed to adapt to life in the context of multi-layer communications, similar to global and inclusive leaders. These new leaders of the future possess, among other skills, the ability to communicate in the intercultural environment [14], and, therefore, are able to instrumentally deal with different forms of literacy, using one or another modality depending on the proposed cultural context. Multiliteracies imply that any amount of information cannot have a long life, because instrumental/functional literacy forms need to be submitted in the course of a lifetime in a variety of forms of literacy, that is, modern people would have to take up a lifelong learning. Generating meanings through changing modalities and acquiring new modalities as they arise [15], using language and communication varieties as a resource, is what makes multiliteracies a productive teaching approach.
The article was prepared with the support of the grant from the Russian Foundation for Basic Research № 1729-09136\18.

\section{References}

1. C.B. Frey, M. Osborne, The Future of Employment. How susceptible are jobs to computerisation (2013).

2. B.B. Kachru, World Engl. J. 9, 1 (1990)

3. New London Group, Harv. Educ. Rev. J. 66, 1 (1996)

4. M. Kalantzis, B. Cope, A. Harvey, Assess. in Educ. J. 10, 1 (2003)

5. G. Kress, Literacy in the New Media Age (Routledge, London 2003)

6. C.B. Cazden, E.L. Leggett, Culturally responsive education: A Response to LAU remedies II, (1976)

7. C.B. Cazden, Classroom discourse. The Language of teaching and learning (Heinemann 2001)

8. G. Kress, Comp. \& Compos. J. 22 (2005)

9. B. Seidlhofer, ELT J. 59, 4 (2005)

10. D. Crystal, English as a Global Language (Cambridge University Press, Cambridge (2003)

11. I.A. Kolesnikova, Lifelong Ed.: XXI cen. J. 2 (2013)

12. A. Sams, J. Bergmann, Educ. Lead. J. 70, 6 (2013)

13. N. Postman, The End of Education. Redefining the Value of School (Vintage Books, A Division of Random House, Inc. New York 1996).

14. A. Bird, M.E. Mendenhall, M.J. Stevens, G. Oddou, J. of Manag. Psych. 25, 8 (2010)

15. G. Cervetti, J. Damico, P.D. Pearson, Theory into pract. J. 45, 4 (2006) 